\title{
Audiometric Test
}

National Cancer Institute

\section{Source}

National Cancer Institute. Audiometric Test. NCI Thesaurus. Code C38036.

Testing conducted utilizing a manual or microprocessor audiometer to test for hearing loss. 